\title{
ASCENDING CYSTIC DEGENERATION OF THE CORD AFTER SPINAL CORD INJURY
}

\author{
By NoRval Watson \\ Lodge Moor Hospital, Sheffield
}

\begin{abstract}
We have reported a series of 15 cases of ascending cystic degenerative myelopathy from a total of I 500 spinal injuries over a period of 30 years, an incidence of I per cent. Although sensory impairment was troublesome in many cases, motor loss was infrequent and minimal and never became severe enough to warrant further investigation or active surgical treatment. A conservative approach is recommended in the management of this complication.
\end{abstract}

Key words: Spinal cord injury; Ascending cystic degeneration; Cervical myelopathy; Conservative management.

THE clinical and pathological features of this interesting complication of spinal cord injury were first described in 1959 by Freeman, who reported on a patient with a D.4 paraplegia, who subsequently developed motor and sensory loss in the arms and who had complete recovery after drainage of a cyst in the lower cervical cord. Strong, in 1919, had already reported a case of spinal cord injury who developed motor and sensory loss in the arms 8 years later. Finkle, in 1960, described six cases of upper limb deterioration following dorsal and dorso-lumbar injuries, but although one of his cases improved after drainage of a cyst just above the level of the injury, he was unsure of the pathological processes involved and suggested either arachnoiditis or ascending vascular infarction as the cause of the complication. But it was Jousse and his colleagues in Toronto in I966 who first accurately described the clinical features and pathological changes in this fascinating complication of spinal cord injury. They presented a detailed study of the problem, recommending myelography as a routine investigation which would reveal a swelling of the cervical spinal cord if one waited long enough. They reported one case with drainage of a large cyst, which had taken several years to be demonstrated radiologically.

Finkle had reported that one of his six cases had a band of normality between the original injury and the secondary ascending lesion and as he had demonstrated a bony spur in the cervical spine he excluded the case from his ascending group of complications. Jousse had also detected this normal gap in two of his eight cases and had offered as his explanation that there was more room in the cervical theca, thereby allowing the cervical cord to expand more easily from pressure from the cystic cavitation, rather than at a lower level. Freeman had given his opinion that a cyst of traumatic origin would expand from pressure within and being limited in caudal growth due to the scarring at the injury site, it would be more free to expand cephalad along the line of less resistance. We have been able to demonstrate that cystic cavitation can be seen at every level in the cord even though clinical signs were confined to the upper parts.

The condition first came to our attention in Sheffield in 1958, when a patient who had suffered a fracture dislocation at the dorso-lumbar junction with partial paraplegia one year previously developed loss of pain and temperature appreciation 
on the left side of the trunk from the D.ro segment upwards over the chest, left arm and left side of the neck to C.2. He had normal sensation from D.Io downwards to L.I segment. Reflexes were absent in the left arm. This analgesia had been preceded by a sharp pleural type pain in the left side of the chest, left arm and left side of the neck and as the pain subsided so the numbness was identified by the patient. He had only slight weakness of the left arm but was troubled more with inco-ordination of the left hand while driving. Nystagmus and diplopia were detected.

We were puzzled by this development and asked our neurological and neurosurgical colleagues for their opinion. Air encephalography and vertebral angiography were performed and found to be normal. Their opinion was that the symptoms and signs were due to vascular insufficiency in the vertebral-basilar system. Over the years this man's sensation deteriorated slowly and I 2 years after the first sign he got weakness of the left arm and later lost the reflexes in his normal right arm. He remains fairly well.

In 1960 we identified our second patient, who, unusually, had a complete tetraplegia below the C.7 level, from an injury 5 years previously. This man developed loss of pain and temperature appreciation up to C.3 on the right side and 2 years later to C.5 on the left side. He had motor weakness for one year but recovered. The sensory loss was permanent.

From I965 onwards we identified a regular sequence of cases with this complication, and the following tables serve to show the sequence of levels, intervals between accident and onset and the clinical features. Fifteen cases were identified out of a total of I 500 cord injuries, an incidence of I per cent.

A study of the tables shows that apart from the single cervical injury, the numbers were equally divided between complete dorsal injuries and partial dorso-lumbar injuries. But since there were double the number of dorso-lumbar injuries compared with dorsal during the years, the incidence of this complication must be twice as high in dorsal as in dorso-lumbar lesions. The number of incomplete dorso-lumbar injuries, six out of seven, who developed this complication is much higher than would be expected from our usual ratio of two complete to three incomplete lesions at that level.

The ages of patients ranged from 2I to 42 years at the time of their injury and from 25 to 58 years at the time of onset of their myelopathy. None of the patients

TABLE A

Dorsal

\begin{tabular}{lcccccccc}
\hline Patient & Year & Level & $\begin{array}{c}\text { Complete } \\
\text { or } \\
\text { partial }\end{array}$ & $\begin{array}{c}\text { Interval } \\
\text { years }\end{array}$ & $\begin{array}{c}\text { Motor } \\
\text { loss }\end{array}$ & $\begin{array}{c}\text { Sensory } \\
\text { loss }\end{array}$ & $\begin{array}{c}\text { Gap } \\
\text { of } \\
\text { normality }\end{array}$ & Deaths \\
\hline H.D. & I955 & C7 & C & 5 & Mild & R \& L & - & \\
B.S. & I956 & D7 & C & I3 & - & L & - & \\
L.S. & I957 & D7 & C & I2 & Mild & L & - & Renal \\
J.D. & I959 & D9 & C & 9 & - & L & - & failure \\
I.A. & I965 & D8 & C & 5 & - & L & - & \\
F.T. & I965 & D9 & C & 5 & - & L & Yes & \\
R.P. & I969 & D5 & C & I & - & L & - & \\
I.S. & I969 & D5 & C & $\frac{1}{2}$ & - & L & - & \\
\hline
\end{tabular}


TABLE B

Dorso-Lumbar

\begin{tabular}{|c|c|c|c|c|c|c|c|c|}
\hline Patient & Year & Level & $\begin{array}{l}\text { Complete } \\
\text { or } \\
\text { partial }\end{array}$ & $\begin{array}{c}\text { Interval } \\
\text { years }\end{array}$ & $\begin{array}{c}\text { Motor } \\
\text { loss }\end{array}$ & $\begin{array}{c}\text { Sensory } \\
\text { loss }\end{array}$ & $\begin{array}{c}\text { Gap } \\
\text { of } \\
\text { normality }\end{array}$ & Deaths \\
\hline A.F. & 1957 & DI2 & $\mathrm{P}$ & I & Mod. & $\mathrm{L}$ & Yes & \multirow{7}{*}{$\begin{array}{l}\text { Pancreatitis } \\
\text { Amyloid } \\
\text { autopsy }\end{array}$} \\
\hline A.P. & I957 & $\mathrm{LI}_{\mathrm{I}}$ & $P$ & 9 & Mild & $\mathrm{L}$ & - & \\
\hline H.B. & 1952 & $D_{12}$ & C & 13 & - & $\mathrm{L}$ & - & \\
\hline H.O'N. & 1953 & DI2 & $P$ & 19 & Mild & $\mathrm{L}$ & Yes & \\
\hline J.L. & 1965 & $\mathrm{LI}_{\mathrm{I}}$ & $P$ & I2 & - & $\mathrm{L}$ & Yes & \\
\hline C.D. & 1959 & Dio & $P$ & 4 & - & $\mathrm{R} \& \mathrm{~L}$ & Yes & \\
\hline J.K. & 1974 & Di2 & $\mathrm{P}$ & I & Mild & $\mathrm{L}$ & - & \\
\hline
\end{tabular}

had a neck injury except the only tetraplegic patient. Four of the others were unconscious at the time of the accident and recovered within a few hours.

Treatment of the original injury did not appear to have an influence on the development of the myelopathy. Six out of the seven dorsal injuries were treated conservatively as is our usual method for dorsal injuries. Four out of the seven dorsal lumbar injuries had had an operation.

The time interval between the original injury and the development of the myelopathy ranged from 6 months to I 3 years in the dorsal group, and from I year to 19 years in the dorso-lumbar group. This variation in the time interval bore no relation to the severity of the secondary defect. Gross sensory loss occurred both after I year and 19 years respectively, and minimal sensory loss occurred after I year and 9 years.

\section{Clinical Picture}

The clinical picture varied from quite minimal sensory loss for spinothalamic function to a fully developed anaesthesia of an arm with some motor weakness and the development of Charcot joints.

The left arm was involved in every case and in two cases the right arm also. I am unable to explain this predilection for the left arm except on anatomical grounds.

The initial presenting symptom was fairly constant in all cases. There was usually a period of some weeks when the patient felt pain and aching in the left side of the chest, left shoulder, neck and even of the face. During this period he was liable to be referred to various clinics because of 'rheumatism' or 'arthritis' and given several methods of physical treatment. Then as the pain receded the numbness became evident. Loss of pain and temperature appreciation was the first symptom noticed by the patient, but I consider that the loss of reflexes in the arms was the first sign for the doctor to elicit if he was consulted early enough during the painful period. The sensory loss was usually progressive and extended up to the C.2 level in most cases in time. In only one mild case did the sensory loss improve. In our series the motor loss was minimal and only six cases had detectable loss of power in the upper limbs. In three of these the motor deficit improved later. The loss of reflexes was usually permanent. 


\section{Charcot Foints}

Two patients developed Charcot type joints, one also with sepsis in the joint as an added terminal complication. Both patients were at the upper age limit of 40 at the time of their accident and over 55 when their myelopathy declared itself. Both had dorso-lumbar injuries and had stood or walked in calipers and crutches for many years.

\section{Lower Limb Changes}

Six out of the seven dorso-lumbar injuries were incomplete lesions with a variety of mostly lumbar segmental sparing so that they used calipers and crutches for ambulation. Two of the six had some deterioration of motor function in the legs but they had reverted to a wheelchair routine early in their paraplegic life and disuse may have played a part in their lumbar segmental deterioration. The other four had remained active walkers without detectable deterioration.

\section{Cranial Involvement}

Only one patient developed signs of cranial involvement. This D.9 paraplegic who had a band of normality up to D.7, had sensory loss up over the neck on to the left side of the face. A much more worrying feature was that for about a year after the onset of the myelopathy he complained of difficulty in speaking loudly. In particular, he said that he could not shout for his dog. This was the only case in which I contemplated further investigation with a view to surgical treatment if a life threatening situation had developed. Fortunately the cranial symptoms resolved within a year but he still had impaired sensation on the left side of the face.

\section{Normal Gap}

Five of our series had clear-cut evidence of a gap of normality between the level of the original injury and the lower level of the cystic myelopathy. This is the most puzzling feature of this complication and as we now all subscribe to the ascending theory of cystic degeneration, it is difficult to explain the normal gap which occurs in some cases. However, despite the normal clinical signs, autopsy has revealed the presence of cysts at all levels in the cord.

\section{Deaths}

Three patients died after the development of this myelopathy. Two died at home, one from pancreatitis, the other from renal failure, and no autopsy was performed. The third death was a dorso-lumbar injury in 1953 with a very incomplete paraplegia who was 39 years old at the time of his injury and who developed signs of myelopathy I9 years later at the age of 58, with sensory loss ranging from D.Io up to C.2 in the left side, associated with some motor weakness. He developed a Charcot joint of the left shoulder and later sepsis in the shoulder. $\mathrm{He}$ died of amyloid disease associated with chronic renal failure and a long history of minor chronic ulceration of the feet and buttocks.

Autopsy demonstrated that there was a large cystic cavity extending from the medulla downwards throughout the entire length of the spinal cord. It was maximal in size in the cervical cord where it was fairly central lying posteriorly to the central canal, extending laterally through the grey matter and extending into 


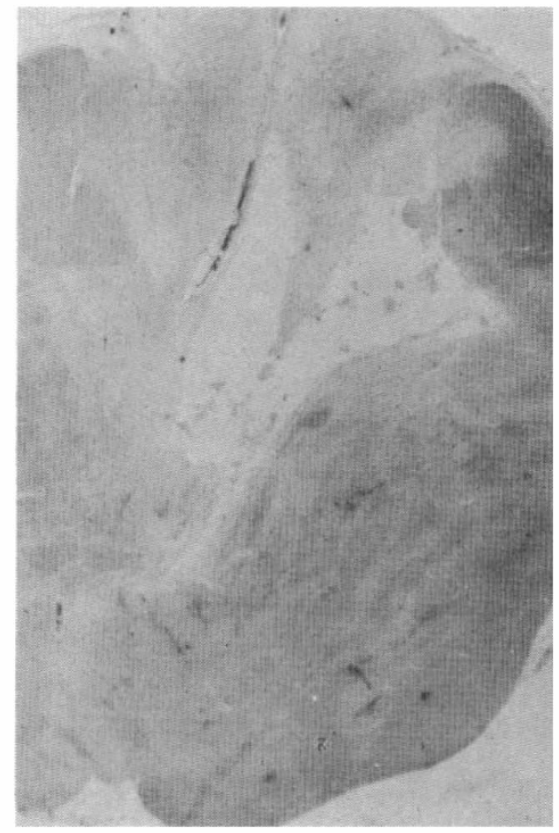

FIG. I

Section of upper cervical cord at CI level with cyst sited posteriorly.
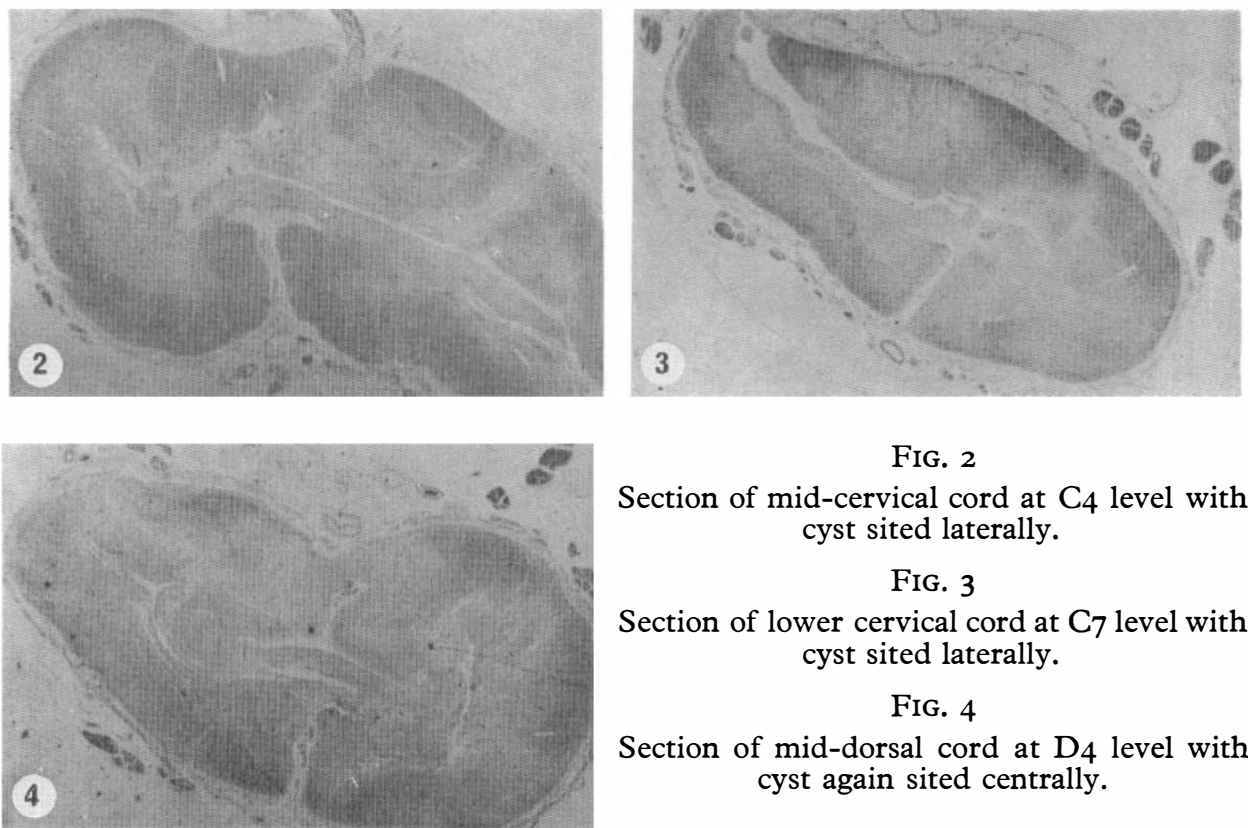

FIG. 2

Section of mid-cervical cord at $\mathrm{C}_{4}$ level with cyst sited laterally.

FIG. 3

Section of lower cervical cord at $\mathrm{C}_{7}$ level with cyst sited laterally.

FIG. 4

Section of mid-dorsal cord at $\mathrm{D}_{4}$ level with cyst again sited centrally. 
the anterior and posterior horns. In the lower cervical cord the cyst was situated more laterally on the left side, displacing the central canal to the opposite side. In the upper dorsal cord the cyst was still laterally sited but in the mid-dorsal cord it was again situated centrally posterior to the central canal encroaching mostly on the posterior horns. In the lower dorsal cord several cavities were identified, the original posterior one, two more at the junction of grey and white matter and one which appeared to be from a rupture of the central canal.

In the lumbar cord several cavities were identified and at the maximum site of damage in the lower lumbar cord a large cyst had replaced the whole posterior aspect of the cord.

No cavitation was seen in the brain stem. Muscle biopsy from the left shoulder demonstrated neurogenic atrophy of the muscle fibres. This man had a gap of normality from D.Io downwards to L.4, despite the presence of multiple cystic cavitation in the cord at, below and above that level.

\section{Investigation and Treatment}

The sensory loss was troublesome and a nuisance to most of our patients, especially where they had difficulty in gauging strength of grip or co-ordination in using the limb. The motor loss however in our series was only minimal in some cases and never became marked enough to consider definitive surgical treatment. The only time we ever considered myelography and surgical drainage was in the case already mentioned who developed sensory loss of the face and difficulty in swallowing and in shouting. This man gave us several anxious months but fortunately the bulbar-signs regressed and he has had no trouble since.

An interesting case was that of a young man with a dorso-lumbar injury at L.V.I at the age of $2 \mathrm{I}$ with a very incomplete paraplegia. His only neurological deficit was weakness of the left foot, requiring the use of a short caliper. He had a laminectomy. Twelve years later he developed sensory loss of pain and temperature from D.I2 up to D.2 and later to C.5 on the left side only with loss of reflexes. His legs were unaffected. During the prodromal period he had the typical pain and aching in the left side of the trunk and as he worked in Europe he was referred to several different types of clinics and treated for a variety of disorders, mostly digestive, before the lesion was diagnosed.

\section{RÉSUMÉ}

Nous avons rapporté sur une série de quinze cas de cystique myélopathie ascendante dégénérative entre $I, 500$ lésions vertébrales admis pendant trente ans, une incidence d'un pour cent. Même que l'altération des sens était ennuyeuse en plusieurs cas, la dégénération musculaire n'a jamais été plus que rare et minimum et n'a jamais justifié ni de recherche de plus ni de l'intervention chirurgicale. Un traitement conservatif est recommandé pour le soin de cette complication.

\section{ZUSAMMENFASSUNG}

Wir berichten I 5 Fälle von aufsteigender, cystischer, degenerativer Myelopathie, die während 30 Jahren in einer Serie von I 500 spinalen Verletzungen auftraten $(=\mathrm{I} \%)$.

Die sensorischen Schädigungen waren in vielen Fällen sehr störend, jedoch motorisches Defizit trat selten auf, war gewöhnlich minimal und führte niemals zu weiteren Untersuchungen oder aktiver chirurgischer Behandlung.

Es wird empfohlen, sich dieser Komplikation gegenüber abwartend zu verhalten. 


\section{REFERENCES}

FINKLE, J. R. (1960). Lesions ascending from spinal cord injuries. Proceedings of the 9th Annual Clinical Spinal Cord Conference, pp. 45-48.

FreEman, L. W. (1959). A case of ascending spinal paralysis. Fournal of Neurosurgery.

Jousse, A. T. et al. (I966). Progressive myelopathy as a sequel to traumatic paraplegia. Proceedings of the 14th Annual Clinical Spinal Cord Conference. Medical Services fournal of Canada, 63I-65I.

\section{Addendum}

Since this paper was written four more cases of this complication have been identified in the Sheffield unit, making a total of 19 cases, an incidence of $1 \cdot 25$ per cent. 